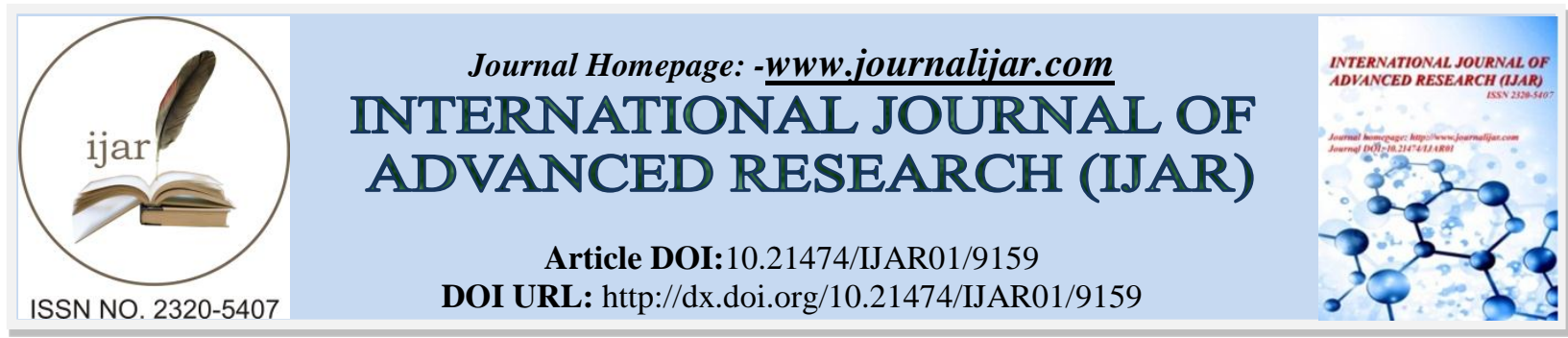

RESEARCH ARTICLE

\title{
COMPARISON OF CONVENTIONAL RADIOGRAPHY AND DIGITAL RADIOGRAPHY IN REGULAR AND REVERSAL IMAGE MODES FOR DETECTION OF PERIAPICAL PATHOLOGY USING INTRAORAL PERIAPICAL RADIOGRAPHS AND ALVEOLAR BONE LOSS DEPTH USING BITEWING RADIOGRAPHS.
}

Dr. N. Krishna Raj ${ }^{1}$ And Dr. K. SaraswathiGopal ${ }^{2}$.

1. Post Graduate student, Department of Oral Medicine and Radiology, Meenakshi Ammal dental college and hospital.

2. Professor and Head, Department of Oral Medicine and Radiology, Meenakshi Ammal dental college and hospital.

\section{Manuscript Info}

\section{Manuscript History}

Received: 24 March 2019

Final Accepted: 26 April 2019

Published: May 2019

\section{Key words:-}

periapical lesion, Radiovisiography , Photostimulable Storage Phosphor plates, Direct Digital radiography.
Abstract

Background: Periodontitis is an inflammatory disease of the supporting tissues of the teeth caused by specific microorganisms, resulting in destruction of the periodontal ligament and alveolar bone. Progressive loss of alveolar bone is the salient feature of periodontal disease. Accurate detection of periodontal disease with the use of radiographs helps in diagnosis, treatment and prognosis.

Aim: The aim of the study is to analyze and compare the efficacy of conventional intraoral periapical(IOPA) and digital radiographs(PSP) in detecting periapical lesion and interdental bone loss depth in chronic periodontitis

Materials and methods: A total of 60 subjects will be included in the study aged between 20-60 years consisting of 30 subjects who have generalized moderate to severe chronic periodontitis, and another 30 subjects with dental caries, history of trauma and discoloration.

Results: The overall results shows the mean difference between both the conventional and digital bitewing radiographs was -0.34883 and the standard deviation difference were 1.137 which is statistically significant. It was observed that digital bitewing radiographs evaluated about $0.3489 \mathrm{~mm}$ greater bone loss on an average than conventional bitewing radiographs. mean difference between both conventional and digital was 0.3917 and the standard deviation difference was 0.04281 which was not statistically significant. It was observed that conventional radiograph shows a greater extent of the periapical pathology, the overall difference is $0.3917 \mathrm{~mm}$ on an average.

Conclusion: With the limitations in this study, We conclude that digital radiography is the choice of imaging modality for interdental bone loss. We found that both digital and conventional radiography more or less have same significant value in detecting periapical lesions. 


\section{Introduction:-}

Oral diagnosis is the art of using scientific knowledge to determine the nature of oral diseases and distinguishing it from other diseases. ${ }^{[1]}$ Clinical examination of contacting approximal surfaces, even under ideal circumstances, results in an unacceptable proportion of false-negative results, especially in the presence of tight contact points that impair inspection.Thus, caries in approximal surfaces has traditionally been diagnosed by clinical examination combined with radiography. ${ }^{[2]}$ The commonly encountered periapical lesions following dental caries or trauma are periapical abscess, periapical granuloma, or periapical cyst. The diagnosis of periodontal diseases and periapical lesions involves careful analysis of the case history and evaluation of the clinical signs and symptoms, as well as the results of various tests like probing, mobility assessment, radiographs, blood tests and biopsies. Accurate diagnosis of periapical lesions may aid not only in predicting the treatment outcome but also may decrease the incidence of root canal treatment failure associated with lack of an appropriate diagnosis. ${ }^{[3]}$

Radiography is a well-established procedure in daily dental practice and is still the most basic and an important diagnostic tool available. . Dental radiography is a very less invasive diagnostic technique primarily used to survey morphological and pathological changes of diagnostic interest in the teeth and jaws. Conventional radiography provides a two-dimensional image of a three-dimensional structure, thus may fail to differentiate a small periapical cyst from a large periapical granuloma, since the major defining parameter taken into consideration is the size of the lesion along with the presence of sclerotic border. ${ }^{[4,5]}$ Conventional bitewing and intra oral periapical radiographs are commonly used to detect alveolar bone loss associated with periodontal disease.

Over the past few years, systems that can generate radiographic digital images without the need for radiography film have become available for use in clinical practice and are gaining popularity among practitioners. Such digital radiography can also reduce the radiation exposure. One of the most useful advantages of digital radiography is the knack it provides to the clinicians to send images to practitioners in a matter of minutes, for which it has become widely accepted as an alternative to film-based radiography. ${ }^{[1]}$ Accurate diagnosis by gold standard histopathology may not be possible at the right juncture or the decisive moment in all cases, thus defeating the ulterior motive of an ideal diagnostic modality and making it impractical for non-surgical cases. ${ }^{[3]}$

Digital imaging has gained popularity due to its reduction in patient exposure, ability to manipulate the image, enhance and analyze it, thus making it appealing. ${ }^{[6,7]}$

\section{Materials And Methods:-}

A total of 60 subjects will be included in the study aged between 20-60 years consisting of 30 subjects who have generalized moderate to severe chronic periodontitis, and another 30 subjects with dental caries, history of trauma and discoloration.

\section{Group 1:}

A series of conventional bitewing radiographs and digital bitewing radiographs with PSP sensors on either side for the molars will be taken for each patient using paralleling technique using Dentsply Rinn XCP Film holding device. The machine used is Satelec X-Mind D. The film used is KODAK Size 2 E Speed Dental Film. The digital sensor used is PSP film and is scanned used Soredex Digora Optime Scanner.

The radiographs will be mounted on x-ray viewer and alveolar bone loss will be measured by keeping the divider on CEJ to the most apical level of marginal bone, transparent ruler will be used to evaluate the distances between the two points of divider. Similarly a series of digital bitewing radiograph will be taken for all the patients by using PSP and the bone loss is measured by using the measure the distance option in the dFW software provided with the Digora Optime Scanner. Radiographically for the measurement of bone levels from both methods we considered normal bone level less than $2 \mathrm{~mm}$ from the CEJ, and above that we measured as bone loss. Bone loss in relation to premolars and molars of both sides were measured and 3 readings were taken from each site and mean of 3 readings is taken as a final readings.

The measurements are repeated in the digital radiograph in reversal image mode also and are also recorded in the same way. 


\section{Group 2:}

The periapical lesion will be measured using divider from the apical foramen till the extension of the lesion in its greatest dimension. The image obtained from the PSP sensor will be also evaluated by linear measurements for all the subjects in the group. The measurements are repeated in the digital radiograph in reversal image mode also and are also recorded in the same way.

\section{Results:-}

\section{Boneloss}

In the current study we radiographically examined 30 patients of which 15 were females and 15 were males. Their age ranged from 18-60years average (36.04). The radiographs were taken for diagnostic purpose such as periodontal examination, periapical disease diagnosis. The collected data was analysed with SPSS software and the significance of result was arrived at.

Sites which are examined and evaluated in conventional radiographs is directly compared in RVG to get a proper correlation in the sites.

Table 1:-Mean Values Of Bone Loss Obtained In The Three Radographic Methods

\begin{tabular}{|l|l|l|l|l|l|l|l|l|l|l|l|l|l|}
\hline & Site & Site & Site & Site & Site & Site & Site & Site & Site & Site & Site & Site & Site \\
& 1 & 2 & 3 & 4 & 5 & 6 & 7 & 8 & 9 & 10 & 11 & 12 & 13 \\
\hline Conventional & 2.96 & 2.93 & 3.16 & 3.21 & 3.3 & 3.65 & 3.64 & 3.66 & 3.62 & 3 & 2.66 & 3 & 2 \\
\hline PSP RVG & 3.16 & 3.34 & 3.71 & 3.66 & 3.78 & 3.81 & 3.7 & 3.67 & 4.12 & 3.53 & 3.06 & 3.6 & 2.7 \\
\hline PSP Inverted & 3.16 & 3.34 & 3.71 & 3.66 & 3.78 & 3.79 & 3.71 & 3.67 & 4.12 & 3.53 & 3.06 & 3.6 & 2.7 \\
\hline
\end{tabular}

Thirty subjects were included in this study to examine 213 sites to detect the bone loss. The overall results shows the mean difference between both the conventional and digital bitewing radiographs was -0.34883 and the standard deviation difference were 1.137 which is statistically significant (Table - 2). It was observed that digital bitewing radiographs evaluated about $0.3489 \mathrm{~mm}$ greater bone loss on an average than conventional bitewing radiographs.

Table 2:-Statistical Analysis Of Bone Loss

\begin{tabular}{|c|c|c|c|c|c|c|c|c|}
\hline & \multirow[t]{2}{*}{$\mathrm{N}$} & \multirow[t]{2}{*}{ Mean } & \multirow[t]{2}{*}{$\begin{array}{l}\text { Std. } \\
\text { Deviation }\end{array}$} & \multicolumn{2}{|c|}{$\begin{array}{l}95 \% \quad \text { Confidence } \\
\text { Interval for Mean }\end{array}$} & \multirow[t]{2}{*}{ Mini } & \multirow[t]{2}{*}{ Maxi } & \multirow[t]{2}{*}{$p$ value } \\
\hline & & & & $\begin{array}{l}\text { Lower } \\
\text { Bound }\end{array}$ & $\begin{array}{l}\text { Upper } \\
\text { Bound }\end{array}$ & & & \\
\hline Conventional & 213 & 3.2394 & .98285 & 3.1067 & 3.3722 & 2.00 & 6.00 & .001 \\
\hline PSP & 213 & 3.5883 & 1.13707 & 3.4347 & 3.7418 & 2.00 & 10.50 & \\
\hline PSPI & 213 & 3.5883 & 1.13707 & 3.4347 & 3.7418 & 2.00 & 10.50 & \\
\hline
\end{tabular}

Thirty subjects with periapical pathology were examined under conventional and digital intra oral radiograph. The linear measurements of the pathology were measured and then compared, the overall results shows the mean difference between both conventional and digital was 0.3917 and the standard deviation difference was 0.04281 which was not statistically significant (Table-3). It was observed that conventional radiograph shows agreater extent of the pathology, the overall difference is $0.3917 \mathrm{~mm}$ on an average.

Table 3:-Statistical Analysis Of Periapical Pathology

\begin{tabular}{|c|c|c|c|c|c|c|c|c|}
\hline & \multirow[t]{2}{*}{$\mathrm{N}$} & \multirow[t]{2}{*}{ Mean } & \multirow[t]{2}{*}{$\begin{array}{l}\text { Std. } \\
\text { Deviation }\end{array}$} & \multicolumn{2}{|c|}{$\begin{array}{l}95 \% \quad \text { Confidence } \\
\text { Interval for Mean }\end{array}$} & \multirow[t]{2}{*}{ Mini } & \multirow[t]{2}{*}{ Maxi } & \multirow[t]{2}{*}{$\mathrm{p}$ value } \\
\hline & & & & $\begin{array}{l}\text { Lower } \\
\text { Bound }\end{array}$ & $\begin{array}{l}\text { Upper } \\
\text { Bound }\end{array}$ & & & \\
\hline Conventional & 30 & 3.6667 & 1.93575 & 2.9438 & 4.3895 & 2.00 & 8.00 & .66 \\
\hline PSP & 30 & 3.2750 & 1.89294 & 2.5682 & 3.9818 & 1.30 & 7.60 & \\
\hline PSPI & 30 & 3.2750 & 1.89294 & 2.5682 & 3.9818 & 1.30 & 7.60 & \\
\hline
\end{tabular}




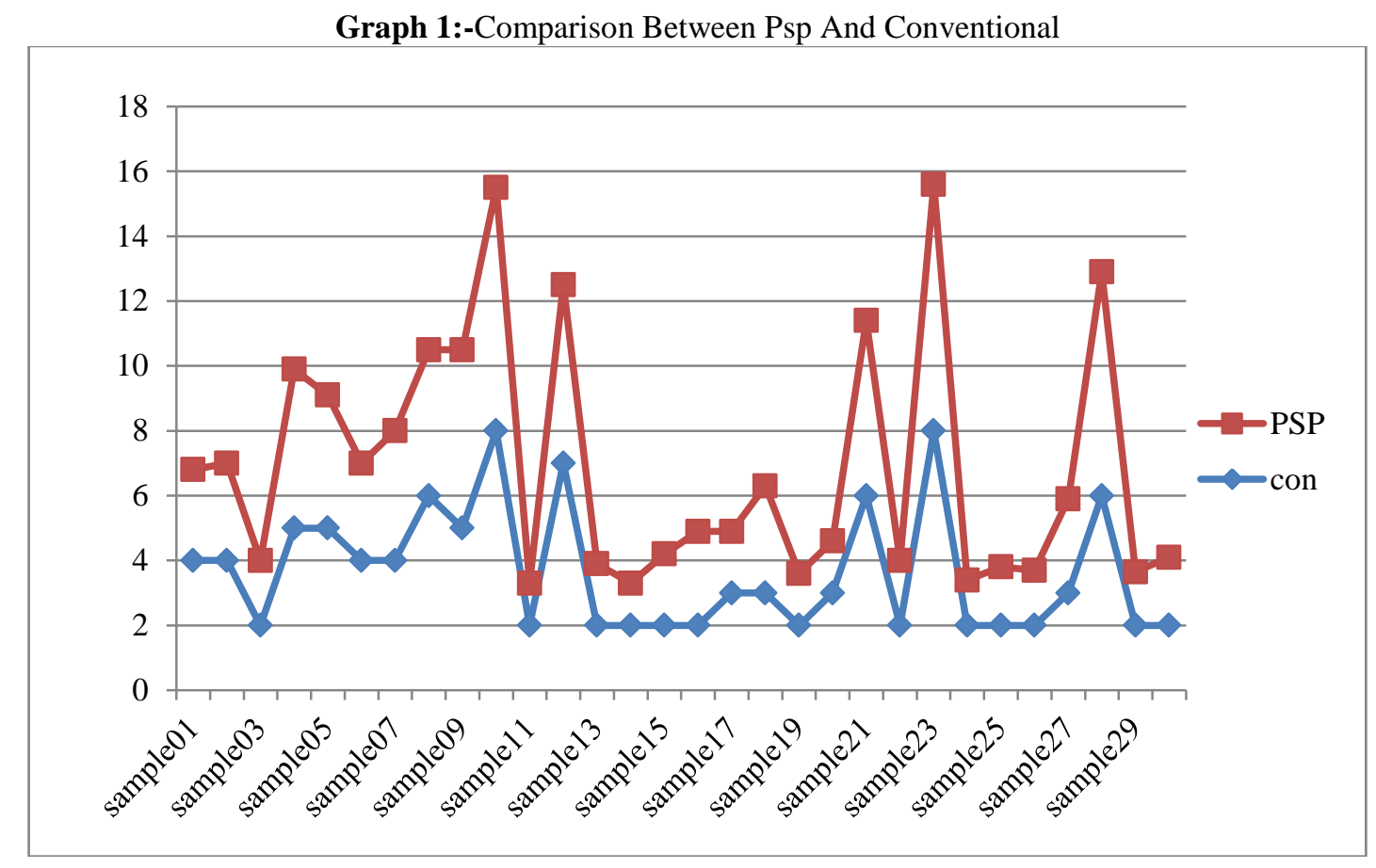

Graph 2: Comparison Between Conventional And Psp And Pspi

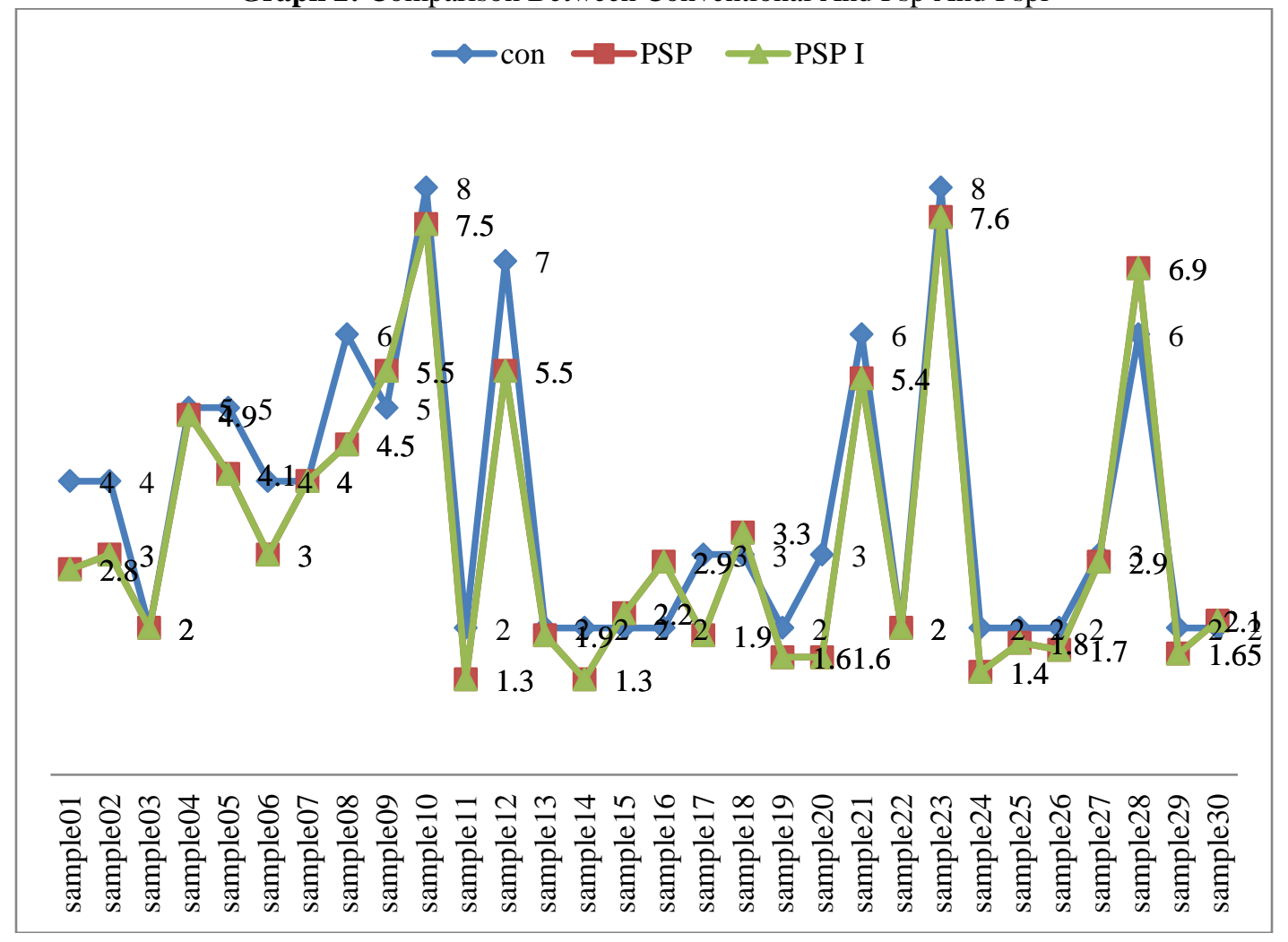

Discussion:-

Khocht et al stated that digital radiography offers many advantages over conventional methods. ${ }^{[1]}$ It eliminates the need for film and film developing, and it allows for lower radiation exposure. The generated image is available immediately for evaluation on a computer screen and can be manipulated digitally to enhance viewing. In addition, 
digital tools are available to record electronic measurements and to cut, paste and colorize the image. The image can be easily filed on and retrieved from the hard disk or removable storage medium, or the images can be transferred electronically to third party carriers. ${ }^{[1]}$

In this study,two observers has examined 30 patients with conventional radiograph and digital radiograph for periapical pathologies and 30 patients with bone loss. For bone loss, 213sites have been examined on both conventional radiographs and PSP, comparison has been done. Also periapical pathology was examined by both the observers in conventional and PSP and compared.

Our study included 60 patient images; 30 in group I and 30 in group II, with equal gender distribution in each group. The mean age of the study population is 36.04 years.

In our study,the mean bone loss measured using conventional radiograph was calculated as $3.2 \mathrm{~mm} \pm 0.9$ with significant $\mathrm{p}$ value of 0.001 . The mean value of bone loss measured using digital radiograph in regular and reversal images was calculated as $3.5 \mathrm{~mm} \pm 1.1$ with significant $\mathrm{p}$ value of 0.001 . The overall results shows the mean difference between both the conventional and digital bitewing radiographs was $0.3 \mathrm{~mm}$ is statistically significant (Table-2). It was observed that digital bitewing radiographs evaluated about $0.3 \mathrm{~mm}$ greater bone loss on an average than conventional bitewing radiographs.

This is in accordance with study conducted by Karanprakash Singh et al in $2015^{11}$ In the study a comparison between conventional radiography (IOPA) and digital radiography using bitewing technique in detecting the depth of alveolar bone loss reported the mean difference between both the conventional and digital bitewing radiographs was 0.4 and the standard deviation difference was 0.2 which was statistically significant. This showed that overall the digital bitewing images averaged $0.4 \mathrm{~mm}$ greater bone loss than did the conventional images with a significant $\mathrm{p}$ value. Similarly, in a study conducted by Ahmed Kotch et al., digital radiography measured $0.3 \mathrm{~mm}$ greater bone loss than conventional bitewings with significant p-value, which is relatively consistent with our results.

Nafise Shamlou Mahmoudi et al in 2009 did a study on Comparison of Digital and Conventional Radiography in Evaluating Horizontal Alveolar Bone Loss and reported the distance between CEJ and alveolar crest by RVG method was $3.53 \pm 1.47 \mathrm{~mm}$ and $2.9 \pm 1.47 \mathrm{~mm}$ by conventional radiography. The difference between digital and conventional radiographic measurements was about $0.6 \mathrm{~mm}$ and was statistically significant $(\mathrm{p}=0.001) .{ }^{8}$ compared to our study, $0.3 \mathrm{~mm}$ distance was more in this study.

The study conducted by Mellekatte C Neetha et al in 2014 on In vivo comparison of Kodak E-speed film and direct digital imaging system for assessment of interproximal bone loss reported the mean difference between the conventional and digital radiographic methods was $0.02 \pm 0.08$. Although difference was statistically nonsignificant $(\mathrm{P}=0.92) .{ }^{9}$ This was almost in accordance with our study.

In the study conducted by Ashwinirani S.R et al on Comparison of Diagnostic Accuracy of Conventional Intraoral Periapical and Direct Digital Radiographs in Detecting Interdental Bone Loss the mean measurements in IOPA were $2.2 \pm 1.14 \mathrm{~mm}$ less than IS measurements. The mean measurements in RVG were $1.5 \pm 0.9 \mathrm{~mm}$ less than IS measurements which was statistically significant $(\mathrm{P}<0.0001) .{ }^{10}$ this was almost in accordance with our study.

In measuring the periapical pathology using conventional method, the mean value was $3.6 \mathrm{~mm} \pm 1.9$ and in digital radiography taken in both regular and reversal images showed mean value of $3.2 \pm 1.8$ and insignificant $p$ value of 0.66. In our study the linear measurements of the periapical pathology measured in RVG showed an mean difference of $0.3 \mathrm{~mm}$ with a standard deviation of 0.04 when compared with the conventional radiograph.

In the studies conducted by Abhishek Aanjan pati et al, Paurazas et al, Holtzmann et al, Mistak et al., no difference in diagnostic accuracy between conventional radiograph and DDR techniques were found in diagnosing periapical lesions. ${ }^{12}$ These studies were not in accordance with our study.

Though other studies are available, no direct comparison could be made because of comparison with IS measurements and ultrasound in our study. 
In the study conducted by Tajinder Kumar Bansal et al,Comparison of diagnostic accuracy of conventional radiography, digital radiography, and ultrasound imaging in the detection of periapical lesions, the diagnostic accuracy of ultrasonography was higher than the observations made by conventional and digital radiographs. When the diagnosis made by conventional radiograph, digital radiograph, and ultrasound were compared with histopathology, there was no significant difference in diagnosis $\left(\mathrm{P}=0.2,0.4\right.$, and 0.7 , respectively). ${ }^{14}$

Purnachandrarao Naik Nunsavath et al in 2015 did a study on Comparison of ultrasound, digital, and conventional radiography in differentiating periapical lesions: An in vivo study stated accuracy of diagnosis in conventional radiography by observer 1 and observer 2 was 93.33\%; similarly, for the digital radiograph, percentage accuracy was $100 \%$. The inter-examiner agreement for ultrasound and histopathology was $90 \%$ with $\mathrm{P}<0.010$ which was considered significant. $^{13}$

In the present study the bone loss and periapical pathology were evaluated using RVG and conventional radiograph and compared which revealed RVG as statistically significant value for detecting bone loss.

The values obtained from RVG and conventional radiography for periapical pathology was not statistically significant since number of cases compared was less.

We observed that in the normal clinical use, significant difference exists between alveolar bone loss measurements on digital and conventional radiographs in several regions in the mouth. This difference noted between the two imaging systems may be attributed to variations in measurements, which were done manually in case of conventional radiographs and digitally in case of digital radiographs, because RVG was showing $0.4 \mathrm{~mm}$ greater bone loss than conventional radiographs while comparing the total samples. These variations may be due to difference in the flexibility of the conventional radiograph film and sensor used in digital radiography.

The results also showed that regardless of digital inverted imaging and regular digital imaging using PSP, there is no difference between bone loss measurements and peripical pathology measurements, which indicates that both methods presented the same reliability. Though, the inverted images may be more useful in extracting the details from the digital radiograph, we did not have any additional benefit in the measurements.

\section{Conclusion:-}

The efficacy of conventional intraoral periapical (IOPA) and digital radiographs (PSP) in detecting periapical pathology and interdental bone loss depth in chronic periodontitis and we found that digital radiography is highly significant in detecting interdental bone loss in chronic periodontitis when compared with conventional radiography. We also found that both digital and conventional radiography more or less have same significant value in detecting periapical lesions.

With the limitations in this study,we conclude that digital radiography is the choice of imaging modality for interdental bone loss.

Further studies are required with more number of samples to detect and compare periapical pathology with conventional radiography and digital radiography to obtain significant value.

\section{References:-}

1. Khocht A, Janal M, Harasty L, Chang KM; Comparison of direct digital and conventional intraoral radiographs in detecting alveolar bone loss. J Am Dent Assc, 2003; 134: 1468-1475.

2. AA Pontual, DP de Melo. Comparison of digital systems and conventional dental film for the detection of approximal enamel caries. J Dentomaxillofacial Radiology 2010 39, 431-436.

3. Ingle JI, Bakland LK. Endodontics. 5th ed. Ontario, Canada: Elsevier; 2002. p. 567-8

4. White SC, Pharoah MJ. Oral radiology: Principles and interpretation. 5th ed. St. Louis, MO: Mosby; 2004. p. 367-70.

5. Tirell BC, Miles DA, Brown CE Jr, Legan JJ. Interpretation of chemically created lesion using direct digital imaging. J Endod 1996;22:74-8.

6. Meier AW, Brown CE, Millis DA, Analoui M. Interpretation of chemically created periapical lesions using direct digital imaging. J Endod 1996;22:516-20. 
7. Barbat J, Messer HH. Detectability of artificial periapical lesions using direct digital and conventional radiography. J Endod 1998;24:837-42.

8. ShamlouMahmoudi Nafise. Comparison of Digital and Conventional Radiography In Evaluating Horizontal Alveolar Bone Loss, 2000 zjrms

9. Mellekatte $\mathrm{C}$ Neetha In vivo comparison of Kodak E-speed film and direct digital imaging system for assessment of interproximal bone loss. Journal of Indian Academy of Oral Medicine \& Radiology | Jan-Mar 2014 | Vol 26 | Issue 1

10. Ashwinirani s.r, comparison of diagnostic accuracy of conventional intraoral periapical and direct digital radiographs in detecting interdental bone loss, journal of clinical and diagnostic research. 2015 feb, vol-9(2): zc35-zc38

11. Karanprakash Singh and Satvinder Singh, Comparision between Conventional Radiography (IOPA) and Digital Radiography Using Bitewing Technique in Detecting the Depth of Alveolar Bone Loss, J Interdiscipl Med Dent Sci 2015, 3:4

12. Abhishek Ranjan Pati. A Comparative Study on Diagnostic Accuracy of Colour Coded Digital Images, Direct Digital Images and Conventional Radiographs for Periapical Lesions - An In Vitro StudyJournal of Clinical and Diagnostic Research. 2014 Nov, Vol-8(11): ZC55-ZC59.

13. Purnachandrarao naik nunsavathu. Comparison of ultrasound, digital, and conventional radiography in differentiating periapical lesions: an in vivo study. 21 journal of indian academy of oral medicine \& radiology | jan-mar 2015 | vol 27 | issue 1.

14. Bansal TK. comparison of diagnostic accuracy of conventional radiography, digital radiography, and ultrasound imaging in the detection of periapical lesions, 521Journal of Indian Academy of Oral Medicine \& Radiology $\mid$ Oct -Dec 2015 | Vol 27 | Issue 4. 